\title{
Prenatal Diagnosis of Lesch-Nyhan Syndrome and Some Characteristics of Hypoxanthine-Guanine Phosphoribosyltransferase and Adenine Phosphoribosyltransferase in Human Tissues and Cultivated Cells
}

\author{
Y. S. SHIN-BUEHRING, M. OSANG, A. WIRTZ, B. HAAS, P. RAHM, AND J. SCHAUB \\ (hildren's Hospital. University of Munich. Munich. Hest (iermam!
}

\section{Summary}

Activities of phosphoribosyltransferase for hypoxanthine and adenine were investigated in erythrocytes and human tissues of fetuses and adults as well as in cultivated fibroblasts and amniotic fluid cells. Kinetic characteristics of these enzymes were also studied in patients with the Lesch-Nyhan syndrome and with partial deficiency for hypoxanthine phosphoribosyltransferase (H(;PRTase), and their obligate heterozygotes. The affinity of HGPRTase for both substrates in partial deficiency decreased to 13 to $20 \%$ of normal and by a less degree in its heterozygotes (50) to $65 \%$ of normal). A slight decrease in the $K_{m}$ for phosphoribosylpyrophosphate was observed in the case of heterozygotes for the Lesch-Nyhan syndrome.

Elevated erythrocytic adenine phosphoribosyltransferase (APRTase) activity was found in fetuses, patients with the LeschNyhan syndrome or with partial deficiency, and in some heterozygotes as well. However, the $K_{m}$ of APRTase for hypoxanthine in these subjects was the same as that in the normal adults. The HCPRTase activity in liver increased almost 4 times during the developmental period, whereas the APRTase activity remained approximately the same. In fetal liver, the APRTase activity was almost two times higher than the HCPRTase activity, whereas in fetal brain the HCPRTase activity was higher. The $K_{m}$ of HGPRTase for hypoxanthine in cultivated cells and human tissues were similar to that in erythrocytes and leukocytes. On the other hand, the HC:PRT ase affinity for phosphoribosylpyrophosphate in these cells was considerably larger than in erythrocytes or in leukocytes.

\section{Speculation}

Aberration in active sites of hypoxanthine phosphoribosyltransferase may be one of the causes for the decrease in enzyme activity in patients with partial deficiency. Phosphoribosylpyrophosphate may stabilize adenine phosphoribosyltransferase but not affect the stability of hypoxanthine phosphoribosyltransferase. Residual activity is often observed in cultivated cells and liver of patients with the Leach-Nyhan syndrome but rarely in their erythrocytes. This may be either due to the lower affinity of erythrocytic enzyme for phosphoribosylpyrophosphate or to the existence of a quite different enzyme in erythrocytes and leukocytes to that in cultivated cells and liver.

The Lesch-Nyhan syndrome is an X-linked recessive disorder characterized by mental retardation, choreoathetosis, and selfmutilation (15). The primary biochemical defect is the absence of hypoxanthine-guanine phosphoribosyltransferase (HGPRTase.
E( 2.4.2.8) leading to increased production of uric acid (25). In erythrocyte hemolysates from patients with the Leach-Nyhan syndrome. phosphoribosyltransferase for hypoxanthine and guanine is virtually absent, whereas that for adenine is increased (25). Although the HGPRTase activity in erythrocyte hemolysates of many obligate heterozygotes is not distinguishable from that of normal $(11,20)$ in their fibroblast cultures, two clonal populations are reported to be present $(18,19,22,24)$, one with normal HGPRTase activity and the other with no activity. Partial deficiency of HGPRTase was reported in a number of patients accompanied by gout but mild or no neurologic abnormalities. These patients were described as having a HGPRTase activity in erythrocytes between 0.01 and $10 \%$ of normal $(1,5,11,13,14,30$. 31). Several studies indicate that this low catalytic activity is associated with altered properties in regard to the inhibition by purine nucleotides, the kinetic characteristics, the sensitivity to thermal inactivation, or the electrophoretic mobility $(1,2,10,11$ $13,17,21,23,33$ )

Willers ot al. (32) have recently described genetic heterogeneity of fibroblast HGPRTase from three families associated with HGPRTase deficiency. They observed differences in hypoxanthine incorporation. resistance to 8 -azaguanine, and activation by lyophilization between fibroblast preparations from patients with the Lesch-Nyhan syndrome and with partial HGPRTase deficiency. In this report, we have further studied the kinetic characteristics of erythrocytic phosphoribosyltransferase with hypoxanthine and adenine as substrates in these patients. We have also investigated the characteristics of the enzymes in human fetal and adult organs and cultivated amniotic fluid cells and fibroblasts. In addition, we report a case of prenatal diagnosis of the LeschNyhan syndrome.

\section{MATERIALS AND METHODS}

$\left[8-{ }^{1.4} \mathrm{C}\right] \mathrm{H} y$ poxanthine and $\left[8-{ }^{1.4} \mathrm{C}\right]$ adenine were purchased from Amersham-Buchler. Braunschweig. West Germany: phosphorihosylpyrophosphate (PRPP), thymidine triphosphate (TTP). and inosine monophosphate (IMP) were purchased from Boehringer Mannheim. Mannheim. West Germany; other chemicals were purchased from E. Merck. Darmstadt. West Germany.

All fetal tissue samples were prepared from legally aborted fetuses aged 22 to $28 \mathrm{wk}$. Tissues were homogenated in 5 volumes of distilled water and kept frozen until used further.

Fibroblast cultures were prepared as described previously (26). Amniotic fluid was obtained from mothers by transabdominal amniocentesis during the 17 th wk of gestation. Amniotic fluid cells were cultured in the same manner as fibroblasts (26). Cultured cells were collected by scraping. washed with saline. dis- 
solved in water, and sonified briefly. The supernatants were used for the further assay. Lysates of human erythrocytes were dialyzed and further prepared as reported previously (13).

The assay mixture for HGPRTase and APR Tase in erythrocytes contained $0.4 \mathrm{mM}\left[8^{-14} \mathrm{C}\right]$ hypoxanthine $(0.04 \mu \mathrm{Ci})$ or $0.2 \mathrm{mM}[8-$ ${ }^{14} \mathrm{C}$ ladenine $(0.04 \mu \mathrm{Ci}), 0.53 \mathrm{mM}$ PRPP, $70 \mathrm{mM}$ Tris-HCl buffer. $\mathrm{pH} 7.4 .3 .3 \mathrm{mM} \mathrm{MgCl}$, and erythrocyte protein equivalent to 0.1 and $0.2 \mathrm{mg}$ hemoglobin in a total volume of $150 \mu \mathrm{l}$. The mixture was incubated for $10 \mathrm{~min}$ at $37^{\circ} \mathrm{C}$, and the incubation was stopped by heating at $95^{\circ} \mathrm{C}$ for $3 \mathrm{~min}$. The phosphoribosyltransferases in tissue and cell homogenates were assayed using $0.67 \mathrm{mM}\left[{ }^{14} \mathrm{C}\right]$

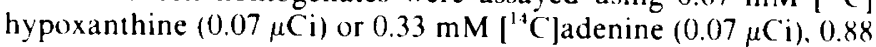
$\mathrm{mM}$ PRPP. $1.7 \mathrm{mM}$ TTP $5.55 \mathrm{mM} \mathrm{MgCl}, 0.1 \mathrm{M}$ Tris-HCl buffer. $\mathrm{pH} 7.4$, and tissue extracts containing 10 to $30 \mu \mathrm{g}$ protein in a total volume of $150 \mu \mathrm{l}$. The mixture was incubated for $60 \mathrm{~min}$. and the reaction was terminated by treating at $95^{\circ} \mathrm{C}$ for $3 \mathrm{~min}$. The blank was prepared without the addition of PRPP. The reaction products, nucleotides, from the substrates, purine bases, were separated with an anion exchange column chromatography using a small plastic syringe. The procedure of the column chromatography is principally the same as that for galactokinase assay or uridyltransferase assay $(27,28)$. The phosphate form of DEAE-cellulose was applied for the chromatography because the $\mathrm{OH}$ form of DEAEcellulose reacts with purine bases and as a consequence disturbs the separation. Purine bases were eluted with water and nucleotides with phosphate buffer or $\mathrm{HCl}$ (Fig. 1).

5 -Nucleotidase which catalyses the conversion of IMP to inosine was the highest in cultivated cells (Table 1). TTP was added to the assay mixture to inhibit the breakdown of IMP to inosine. 5 -Nucleotidase activity was measured using $0.05 \mathrm{M}$ Tris-maleate buffer, $\mathrm{pH} 6.3$ or $\mathrm{pH} 7.4,1.0 \mathrm{mM}$ inosine monophosphate, $5 \mathrm{mM}$ $\mathrm{MgCl}_{2}$, and the sample containing 10 to $20 \mu \mathrm{g}$ protein in a total volume of $200 \mu \mathrm{l}$. After incubating $1 \mathrm{hr}$ at $37^{\circ} \mathrm{C}$, the reaction was stopped with $200 \mu 120 \%$ trichloroacetic acid. The free phosphate

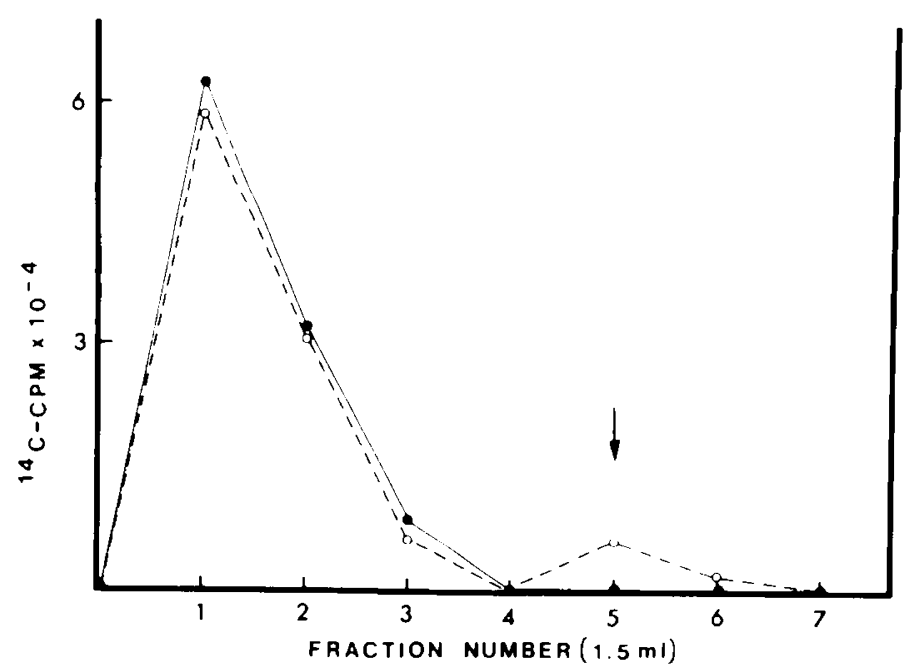

Fig. I. Separation of the product. $\left.\right|^{14} C^{\prime} \mid I M P$, from $\left.\right|^{14}\left(C^{\prime}\right.$ hypoxanthine Fractions 1 to 4 were eluted with water and contain hypoxanthine, and fractions 5 to 7 were eluted with $0.1 \mathrm{~N} \mathrm{HCl}$ and contain IMP. The reaction mixture containing extract of amniotic tluid cells fequivalent to approximately $50 \mu \mathrm{g}$ protein) was incubated for $0 \mathrm{~min}(0)$ and for $60 \mathrm{~min}(1)$ at $37^{\circ} \mathrm{C}$

Table 1. The activity of $5^{\prime}$-nucleotidase

$\begin{array}{lcc}\quad & \text { SH } 6.3 & \mathrm{pH} 7.4 \\ \text { Fetal liver } & 8.2-10.2 & 5.9-10.2 \\ \text { Adult liver } & 5.9-11.2 & 5.2 .5 .8 \\ \text { Fetal brain } & 1.5-1.9 & 1.7-3.5 \\ \text { Amniotic fluid cells } & 61.3-94.3 & 59.3-84.6 \\ \text { Fibroblasts } & 23.6-140.0 & 37.0-160.0\end{array}$

'nmoles phosphate produced per min per mg protein. released from IMP in the supernatant was determined by using the assay kit from E. Merck.

Protein was determined by the micro-method of Lowry et al. (16)

\section{RESULTS}

\section{THI PHOSPHORIBOSYITRANSFERASE IN ERYTHROCYTES}

As shown in Table 2, there was no difference in the HGPRTase activity between fetal and adult erythrocytes, whereas the APRTase activity in fetal erythrocytes was much higher than that in adult erythrocytes. The HGPRTase activity in erythrocytes from the heterozygotes for the Lesch-Nyhan syndrome was in the range of normal adults, but a slightly elevated level of APR Tase activity was found in these heterozygous subjects (Table 2). Patients with the Lesch-Nyhan syndrome showed absolutely no HGPRTase activity in erythrocytes, but had a three times higher level of normal activity of APRTase. The phosphoribosvltransferase activities in erythrocytes from various genotypes of the partial deficiency for HGPRTase are also summarized in Table 2. T. H shows the symptoms of mild mental retardation and hyperuricemia, and $\mathrm{Hg}$. $\mathrm{H}$. is aggressive and shows a minimal brain dysfunction. The heterozygotes for the partial deficiency revealed approximately $30 \%$ of the normal HGPRTase activity, and the patients with the partial deficiency showed 12 to $18^{\prime \prime} "$ of normal.

An increased amount of the APRTase activity was obtained from the patients and also the heterozygotes for the partial deliciency. The apparent $K_{m}$ 's of HGPRTase and APRTase in erythrocytes are shown in Table 3 . The $K_{m}$ of HGPRTase for hypoxanthine from mothers heterozygous for the Lesch-Nyhan syndrome is similar to the normal value (Table 3 ). On the other hand. a slightly elevated $K_{m}$ for PRPP was obtained from the same subjects in comparison with the normal value. From two patients with the partial deficiency, a much lower affinity of erythrocyte HGPRTase for the substrates was found (Table 3; Figs. 2 and 3). Also. a slightly lower affinity of HGPRTase for the substrates was obtained from the heterozygotes for the partial deficiency in comparison with the normal values. In the case of APRTase, there was no significant difference among the $K_{m}$ 's from various genotypes of IIGPRTatse deficiency. Ior both phosphoribosyliransterases, no noticeable developmental changes occurred in regard to the enzyme affinity for the substrates.

\section{THE PHOSPHORIBOSYITRANSFERASE IN HUMAN TISSUES ANI)} CULTURED CHLLS

The specific activity of HGPRTase in liver tissues was somewhat higher than that in cultured cells (Table 4) and that of previously reported values of human liver enzymes (11). The HGPRTase activity in adult liver was much higher than that in fetal liver. whereas the APRTase activity remained more or less the same through the developmental period (Table 4). A considerable

Table 2. The activity of HGPRTase and APRTase in erithrocites from various variants ( $\mu \mathrm{mol} / \mathrm{min} / \mathrm{g}$ hemoglohin)

$$
\text { Source }
$$

Adult $(5)^{\prime}$

retus (2)

Lesch-Nyhan syndrome (6)

Ileterozygote for the Lesch-Nyhan syndrome (2)

Partial deficiency

T. H.

Hg. II.

Heterozygote for partial deficiency

( . W.

Hd. H.

'Numbers in parentheses, number of samples assayed

Mean \pm S.I)

\begin{tabular}{ll} 
HCiPRTase & \multicolumn{1}{c}{ APRTase } \\
$3.3 \pm 0.52^{-}$ & $0.72 \pm 0.16$ \\
3.21 .2 .37 & 1.45 .1 .47 \\
0 & $2.20 \pm 0.24$ \\
2.60 .2 .88 & $0.81,0.93$
\end{tabular}

0.40

0.93

(). 6.3

I. 63

1.30

0.70

$\begin{array}{ll}0.95 & 1.30 \\ 1.03 & 0.70\end{array}$


Table 3. The Michaelis constants of HGPRTase and APRTase in ervthrocytes

$$
\mathrm{K}_{111}(\mathrm{mM})
$$

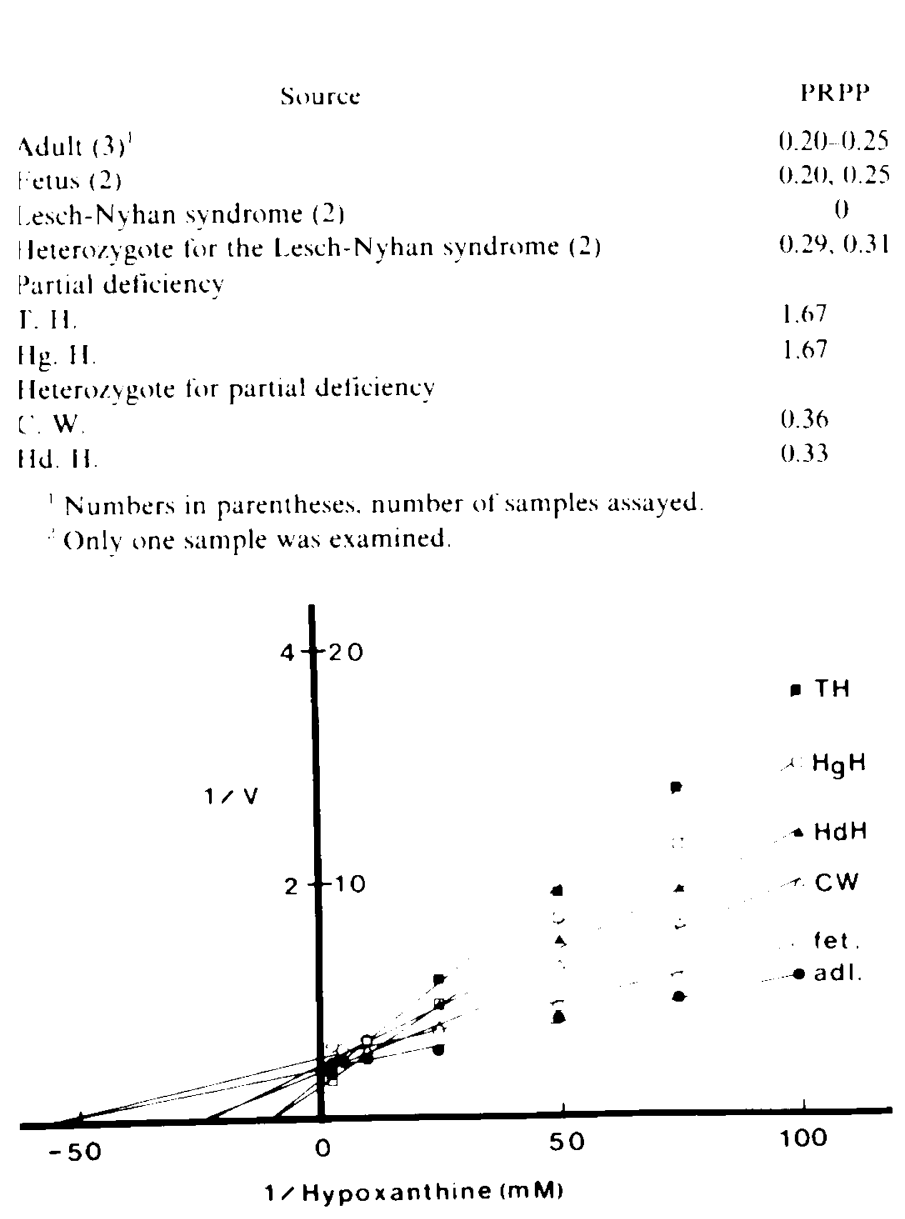

I:ig. 2. Lineweaver-Burk plots of HGPRTase in erythrocytes for hyxoxanthine $(\therefore, W$. and Hd. H. heterozygote partial deficiency. T. H. and Hg. H., partial deticiency. fet., fetus, adl, aduh.

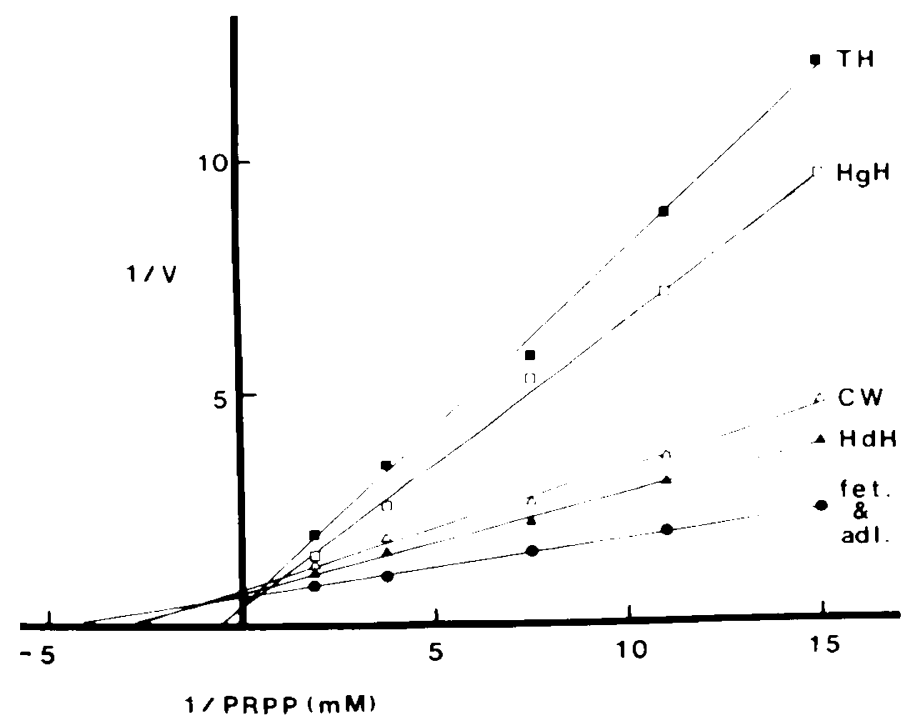

1.ig. 3. Lineweaver-Burk plots of H(iPRTase in erythrocytes for PRPP Same abbreviations as in Figure 2.

amount of both phosphoribosyltransferases was found in fetal brain. i.e. the level is somewhat higher than that in fetal liver, indicating a significant contribution of brain tissue to purine metabolism.
HGPRTase

Table 4. Activities of HGPRTase and APRTase in human tissues, (ultivated cells, and leucocytes (nmoles $/ \mathrm{min} / \mathrm{mg}$ protein)

\begin{tabular}{llll}
$\quad$ Sample & $n$ & HGPRTase & APRTase \\
Fetal liver & 4 & $2.29 \pm 0.12^{1}$ & $4.27 \pm 0.18$ \\
Adult liver & 3 & $9.14 \pm 2.97$ & $4.88 \pm 0.96$ \\
letal brain & 4 & $2.50 \pm 0.35$ & $1.27 \pm 0.10$ \\
Amniotic cells & 4 & $1.26 \pm 0.25$ & $1.59 \pm 0.58$ \\
libroblasts & 3 & $2.11 \pm 0.30$ & $1.70 \pm 0.57$ \\
Leukocytes & 3 & $2.72 \pm 0.18$ & $2.92 \pm 0.12$ \\
\multicolumn{1}{c}{ 'Mean \pm S.D. } & & &
\end{tabular}

Table 5. The Michaelis constants of HGPRTase in human tissues and cultivated cells

Substrate $(\mathrm{mM})$
Sample

fetal liver

Adult liver

Fetal hrain

Amniotic cells

Fibroblasts

Leukocyte:

Erythrocytes

\section{PRPP}

$0.055,0.075$

$0.070,0.133$

0.068 .0 .080

0.044 .0 .05

0.071

$0.20,0.22$

$0.20,0.25$
Hypoxanthine

$0.027,0.033$

$0.022,0.025$

$0.020,0.031$

0.018 .0 .020

0.020

0.020 .0 .015

0.018 .0 .020
The Michaelis constants of the phosphoribosyltransferases in human tissues and cultured cells are summarized in Table 5. The Michaelis constants of HGPRTase for hypoxanthine and PRPP in fetal tissues are in the range of 0.018 to $0.033 \mathrm{mM}$ for hypoxanthine and 0.055 to $0.080 \mathrm{mM}$ for PRPP. These values are similar to the values found in adult liver, cultured fibroblasts, and amniotic fluid cells (Table 5).

In leukocytes, however, the $K_{m}$ for PRPP is much higher than are those in other tissues except erythrocytes in which the $\mathbf{K}_{m}$ was the same as in leukocytes (Table 3 ). These results suggest that HGPRTase in leukocytes and erythrocytes may possess somewhat different characteristics to other tissues.

\section{PRENATAL DIACINOSIS OF: THE LFSCH-NYHAN SYNDROME}

A case of prenatal diagnosis was performed by measuring the HGPRTase activity in cultured amniotic fluid cells. Amniotic fluid was obtained by a transabdominal amniocentesis of an obligate heterozygote for the Lesch-Nyhan syndrome during the mother's 17 th gestational wk. The cells were cultured until confluency, and the HGPRTase activity was measured in different subcultures. As shown in Table 6, the HGPRTase activity in the cultured amniotic fluid cells was much lower than the normal 
Table 6. Prenatal diagnosis of the Lesch-Nihan sindrome

\section{Amniotic fluid cells}

(ontrol'

$\mathrm{Zm}$

0.92 .1 .10

Fihroblasts

control'

Mutant"

Zm

Fetal liver

(iontrol'

$2 \mathrm{~m}$

0.033 .0 .08

2.60. 3.00

$0.05,0.05$

$0.25,0.22$

253

0.14

' Control cells were groun and subcultured as the cells of $\mathrm{Zm}$. and values indicate the activity in the subculture

Mutant fibroblasts were obtained from the Human (ienetic Mutant (ell Repository, Camden. N. J.. U. S. A

value (7) and is in the range of pathologic values of cultured fibroblasts. On the basis of these results together with other pathologic indications (34), the parents decided to have the pregnancy terminated. The samples of cultured fibroblasts and liver tissue from the aborted fetus were examined further. The HGPRTase activity in the liver was much lower than the control value (Table 6; Ref. 8). However. from cultured fibroblasts, a considerable amount of the HGPRTase activity was found (approximately 10 to $15 \%$ of normal). The existence of a considerable amount of HGPRTase in homozygote fibroblasts is described often in the literature $(6,29,32,33)$.

\section{DISC USSION}

Borden et al. (4) reported that the mean value of the APRTase activity in neonates is significantly higher than that in adults. The elevated activity of APRTase was explained partly by a stabilizing effect of PRPP on the enzyme in view of the higher concentration of erythrocyte PRPP in the neonate (4). The increased level of APRTase in patients with the Lesch-Nyhan syndrome and the partial deficiency for HGPRTase $(5,25,31)$ may also be due $(0$ the increased concentration of PRPP in these subjects $(6,9)$.

Almost no difference in the activity and also the affinity of erythrocyte IIGPRTase was observed between normal adults and heterosygotes for the Lesch-Nyhan syndrome. However, the heterozygotes for the partial deficiency showed a much lower HCiPRTase activity in erythrocytes. and furthermore. the enzyme characteristics were different from that of normal adults, i.e.. the $\mathrm{K}_{m}$ for PRPP increased by $50 \%$; and that for hypoxanthine increased by more than lo()" In the case of HGPRTase, in red blood cells there exists a parallel correlationship between the enzyme activity and the enzyme affinity for the substrates. Several other authors $(3,10,11,13,17,21)$ reported that a group of partial deficiencies was associated with altered kinetic properties of HGPRTase in red blood cells. The Michaelis constant for hypoxanthine or PRPP was considerably times higher in these patients.

Only a few studies on phosphoribosyltransferases in amniotic fluid cells and leukocytes were reported until now. The HGPRTase activity in amniotic fluid cells is considerably lower than that in fibroblasts. but APRTase activity is in the same range as in fibroblasts. The specific activity of HGPRTase is found to be the highest in adult liver, showing a four-fold increase during the development. The APRTase activity. on the other hand. remains more or less the same during this period. This result is comparable to the case of erythrocytes where a very high level of the APRTase activity was found in fetuses and newborn infants. In fetal brain, the specific activity of HGPRTase is relatively high. whereas that of APRTase is lower than in other tissues investigated. It would he interesting to study the level of the phosphoribosyltransferase activities in adult brain to compare the developmental aspect with the liver enzymes. The apparent $\mathrm{K}_{m}$ of HGPRTase for hypoxanthine is similar in all tissues studied. however, there is a tissue variation in the $\mathrm{K}_{m}$ for PRPP. i.e. a higher $K_{m}$ was obtained from leukocytes and erythrocytes, and a lower $\mathrm{K}_{m}$ was obtained from amniotic fluid cells compared to that from other tissues. These observations suggest the heterogeneity of phosphoribosyltransferases from various human tissues in regard to their development or the kinetic characteristics such as the affinity and the stability. It may be necessary to study further the kinetic characteristics as well as the isoenzyme patterns of cultured cells and liver tissue from various types of HGPR Tase deficiencies.

\section{RLFERIN(IS ANI) NOTES}

1. Amold. W J.. Meade, J. ( . and Keltey, W. N.: IIGiPRTase: characteristics of the mutant ensme in erythrocytes from patients wath the lesch-Nyhan vindrome. J Clin. Invest. 51 : 1815 (1972)

2. Bakay, B. Nyhan, W. I.. Fawcett, N. and Kogut, M. I). Iscrensemes of hypoxanthine-guanine phosphoribosyleransterase on a family with partial de ficlency of the ensyme. Biochem. (ienet. - 73 (1472).

3. Benke. P. J. Herrick. N.. and Herbert. A.: Hypoxanthine-guanine phosphoribustransterate variant asweclated with accelerated purine synthesis. J (Jin Invest. $52.2234(1973)$.

4 Burden. M. Nyhan. W. I.., and Bakay, B.: Increased atowity of adenine phom phorshosyleransferase in erythrocyten of normal newhorn infants. Pediatr. Res i. $31(1974)$

5. Bunn. 1). N. Mow, I. K.. Nicholls. A. Scott. J. T.. Snaith. M. L.. and Watson. M. R. ( linical and biochemical observations on three cases of hypoxanthineguanine phosphoribosyltransferase deficiency. Ann. Rheum. I)is. it: 249 (1475).

6. (rawhall. J. ( .. Hendersun. J. F.. and Kellev. W. N.: Dlagnosis and treatment of the l.esch-Nyhan syndrome. Pediatr. Res. o: $5(14$ (1972).

7. Demars. R. Sarto. (i.. Felix. J.. and Benke, P.: I esch-Nyhan mutatwen: prenata detection with amniotic fluid cells. Science (Wash. D). (.). lot: 1313 (1964)

S. Tujimoto, W. Y. Seegmiller. J E.. Uhlendort. B. W.. and Jacohon. ( B Burchemical diagnoss of an $X$-linked disease in uere. Lancet. 51$](196,8)$.

9. (ireene. M. L.. Burle, J A.. and Seegmiller. J. A. Substrate stabilization genetically controlled reciprocal relationship of two human ensymes. Science i Wash. D) ( .) $10^{-}: 8 \times 7$ (1970)

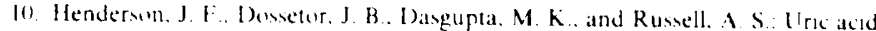
lithasis ansociated with altered kinetics of hypoxanthine-guanine phosphorihowyltransterase. ( lin. Biochem. 9:4 (1976).

11. Kelley. W. N. Cireene, M. 1... Rusenbloum. F. M. Henderson. J. F. and Seegmiller. I. F.: Hypoxanthine-guanine phosphoribonvltransterase deficiency in gout. Ann. Intern. Mad. 7): $155(1969)$.

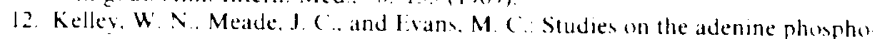
ribosylt ransferase ensyme in human fibroblasts lacking hypoxanthne-guanne

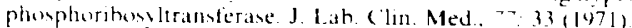

13. Kelley. W. N. Rusenblum. F. M.. Henderson. J. F. and Seegmiller. J. F.. A specific ensyme defect in gout associated with overproductson of uric atcod

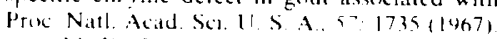

14. Kugut. M. 1). Donnell. (i. N.. Nuhan. W. L... and Sweetman. I... Dinorder of purnc metabolism due to partial deticiency of HeiPRTase. I study of a lamuly Im. J. Med. ts: 148(1970)

15. Iesch. M1.. and Nyan. W I.: A tamilial disorder of urte acid metabolism and central nerwous ivisem function. Am. J. Med. 3t: $561(1964)$.

16. Lowry. (). H. Ronehrough. N. T. Farr. A. I... and Randall. R J Proten meatsurement with the Folin phenol reagent. J. Biol. (hem.. 103: $205(1951)$

17. M(d) mald. J. A.. and Kelley, W. N.: I ésch-Nyhan syndrome altered kinetic properties of the mutant ensme. Science (Wash. D). ( .). $1: 1$ : 689 (1971)

18. Migeon. B. R. Studies of skin fibroblasts from lo families with H(iPRT deficiency with reference to $X$-chromosomal inactivation. $\mathrm{Am}$, Hum Genet. ?.: $\mid 49\{|197|$

19. Migeon. B. R. Kaloustian. V. M.. Nyhan. W L.. Young. W. J.. and ( hilda, B. X-linked hypoxanthine-guanine phosphoribosyltransferase deficuencw: hetero-

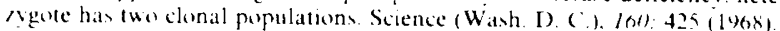

20. Nyan. W I.. Bakay. B.. (onnor, J. D). Marks, J. F., and keele. I) K : Hemisgous expression of glucose-(1)-phosphate dehodrogenase in erythrocites of heterosgetes for the Lexch-Nyhan sydrome. Proc. Natl. Acad. Sci. II. S. 1. $0.5: 21.7(1970)$.

21. Richardorn. B. J. Rychonan. D. L.. Komarnicks. L. M., and Hamerton. J. I. Heterogenety in the hiochemical chasacteristics of red blood cell hypoxanthine-guanue phosphoriboviltranserase from two unrelated patients with the lesch-N whan sindrome. Biochem. (ienet. Q: $197(1973)$

22. Ronenhloem. F. M. Kelley. W. N.. Henderson. J. F. and Seegmiller. J. E.: L von hypothesis and $X$-linked disease. Lancet. 3115: 2775 (1967).

23. Rubin. (C. S. Dancis. J.. Yip. I.. C . Nowinski. R. C and Balis, M. E.. Puritication of IMP: pyrophosphate transterase. catalvtically incompetent ensymes in the lexch-Nyan disease. Proc Natl. Acad. Sci. U. S A o, 1461 (1971)

24. Salzmann. J. Demar, R. and Benke, P. Single-allele expression at an X-linked hyperuricemia licus in heterozygous human cells. Proc. Natl. Acad. Sci. II. S A.. $(1): 545(1906)$

25. Seegmiller, J. F., Rosenbloom. F. M. and kellev. W. N Enzme defect associated with a sex-linked human neurological disorder and expresive purine synthesis. Science (Wash. I). ( ) . 155: 1682 (1967)

26. Shin-Buehring. Y.. Ieitner. H. Henseleit. H.. Wirte. A.. Haas, B.. and Schaub. J.: ( haracteristicis of gatactokinase and galactose-1-phosphate uridyltransterase in cultuated tihroblasts and amniotic fluid cells. Hum. (ienel. As: 31 (1979)

27. Shin-Buehring. Y.. Oaang. M.. Ziegler. R.. and Schaub. J.: A method for 
galactose-1-phosphate uridyltransterase assay and the separation of its isoenzines by DEAE-cellulose column chromatography. ( Clin. ('him. Acta, 70: 371 (i.976).

28. Shin-Buehring. Y.. Osang. M., Ziegler. R., and Schaub. J.: A simple assay for galactokınase using DEAL-cellulose column chromatography. Clin. ('him. Acta. 4: 1 (1977)

24. Singh. S. Willers. I.. and (ioedde, W.: A rapid micromethod for prenatal diagnosis of l.esch-Nyhan syndrome. (lin. (ienet., 10: 12 (1976).

30. Sperling. O.. Frank, M.. Ophir, R., Liberman. U. A.. Adam, A.. and de Vries, A.: Partial deficiency of hypoxanthine-guanine phosphoribosyltransferase associated with gout and uric acid lithiasis. Eur. J. (Clin. Biol. Res.. 15: 942 (1970).

31. Toyo-Oka. T.. Hanaoka. F.. Akaoka. I. and Yamada. M.: X-linked hypoxanthine-guanine phosphoribosyltransferase deficiency without neurological disorders. A report of a family. Clin. Genet. $7: 181$ (1975).

32. Willers. I.. Held. K. R.. Singh. S.. and (joedde. H. W.: (jenetic heterogeneity of hypoxanthune-guanıne phosphoribosyltransferase in human tibroblasts of 3 families. Clin. (jenet.. 11: 193 (1977).

33. Zoret. F.. Sperling, O.. and de V ries. A.: Abnormal properties of human mutan hypoxanthine-guanine phosphoribosyltransferase: insensitivity of fibroblas ensome to stabilization against freezing and thawing by 5-phosphoribosyl-1. pyrophosphate. Eur. J. Clin. Invest.. 4:43 (1974).

34. Information provided by Dr. F. Kollmann from "Zentrum fur Kinderheilkunde." Irankfurt West Germany. Other indications: the pathological levels of uric acid and oxypurine concentrations in amniotic fluid.

35. Requests for reprints should be addressed to: J. Schaub, M. D., Kinderklinik der Universitat. Lindwurmstrasse 4. D-8000) Munchen 2. West Germany

36. This research was supported by Grant Scha $121 / 8$ and $\mathrm{Mu} 258 / 12 \mathrm{a}$ of the Deutsche Forschungsgemeinschaft.

37. Received for publication June 18, 1979.

38. Accepted for publication August 14, 1979. 